\title{
Intrathecal chemotherapy as a treatment for leptomeningeal metastasis of non-small cell lung cancer: A pooled analysis
}

\author{
YA-LAN WU ${ }^{1-3}$, LIN ZHOU ${ }^{2,3}$ and YOU LU ${ }^{2,3}$ \\ ${ }^{1}$ Department of Oncology, Chengdu Shang Jin Nan Fu Hospital; ${ }^{2}$ Department of Thoracic Oncology, Cancer Center; \\ ${ }^{3}$ State Key Laboratory of Biotherapy, West China Hospital, West China Medical School, \\ Sichuan University, Chengdu, Sichuan 610041, P.R. China
}

Received March 27, 2015; Accepted April 22, 2016

DOI: $10.3892 / \mathrm{ol} .2016 .4783$

\begin{abstract}
Leptomeningeal metastasis (LM) is increasingly common in patients with non-small cell lung cancer (NSCLC) due to improved treatment, and ultimately, prolonged patient survival. The current study is a pooled analysis that evaluated intrathecal chemotherapy (ITC) as a treatment for NSCLC patients with LM. The PUBMED, OVID, EBSCO and Cochrane Library databases were searched for published studies involving ITC in NSCLC patients with LM. The primary outcomes of interest included response (symptomatic, radiographic and cytological) and survival. Overall, 4 prospective studies and 5 retrospective studies were included. In total, 37 patients received ITC only, and 552 patients received multiple interventions (ITC, whole-brain radiotherapy, epidermal growth factor receptor tyrosine kinase inhibitors, systemic chemotherapy and support care). In patients with available individual information, the reevaluated cytological, clinical and radiographic rates of response to ITC were $55 \%$ (53-60\%; $n=49), 64 \%(53-79 \% ; n=58)$, and 53\% $(n=32)$, respectively, and the reevaluated median survival time (from the onset of treatment, $\mathrm{n}=50$ ) was 6.0 months (95\% CI, 5.2-6.8). In patients without available individual information, the reported cytological and clinical rates of response to ITC are 14-52\% and $13-50 \%$, respectively, and the reported median survival time (from the diagnosis of LM) was 3.0-4.3 months. The clinical response rates of patients only receiving ITC varied from 71 to $79 \%$ (100\% if including stable disease). The median survival time of patients who only received ITC (7.5 months) was much longer than that of patients who received multiple interventions (3.0-5.0 months). Accordingly, in NSCLC
\end{abstract}

Correspondence to: Professor You Lu or Dr Ya-Lan Wu, Department of Thoracic Oncology, Cancer Center, West China Hospital, West China Medical School, Sichuan University, 37 Guoxue Lane, Chengdu, Sichuan 610041, P.R. China

E-mail:radyoulu@hotmail.com

E-mail: croweggwu@outlook.com

Key words: non-small cell lung cancer, leptomeningeal metastasis, intrathecal chemotherapy, multidisciplinary therapy, survival patients with LM, ITC may offer a promising response rate and survival benefits under a suitable regimen. In addition, a suitable combination strategy of multidisciplinary therapy is extremely important for these particular patients.

\section{Introduction}

As the survival times of non-small cell lung cancer (NSCLC) patients have been significantly prolonged in recent years, leptomeningeal metastasis (LM) has exhibited a tendency for increasing in these patients (1-3). The median survival time of NSCLC patients with LM is $\leq 2$ months if the patients do not receive any treatment $(1,4)$.

For the treatment of LM in NSCLC patients, numerous different interventions and regimens [such as radiotherapy, epidermal growth factor receptor tyrosine kinase inhibitors (EGFR TKIs), systemic chemotherapy, intrathecal chemotherapy (ITC)] have been attempted. Although each intervention has been reported to be effective, no intervention has been confirmed to be the most effective (5-14). In fact, the most effective intervention has not been established for LM from many other types of tumor (15-18). This is predominantly due to the lack of randomized clinical trials (RCTs). Despite its rapidly increasing incidence, $\mathrm{LM}$ remains a rare complication of NSCLC. The very limited number of patients significantly restricts the implementation of RCTs.

Recently, it was noted that WBRT may have no contribution to the survival time of patients with $\operatorname{LM}$ from $\operatorname{NSCLC~}(3,10)$. It has been proposed that ITC may offer more benefits, according to the results of two retrospective studies analyzing the connection between treatment and clinical outcome in NSCLC patients with LM (2). Thus, in order to better evaluate ITC as a treatment for these particular patients, a pooled analysis of eligible clinical studies was conducted in the present study.

\section{Patients and methods}

Studies. A systematic search of the (http://www.ncbi.nlm. nih.gov/pubmed), OVID (http://ovidsp.ovid.com/autologin. html), EBSCO (http://search.ebscohost.com), and Cochrane Library databases (http://www.thecochranelibrary.com) was performed to identify all clinical studies that contained NSCLC patients with LM that were treated by ITC. The search 
strategy included articles indexed under the subject headings 'cancer', 'tumor', 'carcinoma', 'neoplasm', 'carcinomatosis', 'malignancy', 'meningitis', 'meningeal', 'leptomeningeal', 'metastasis' and 'metastases'. The latest search was conducted on July 31, 2014. The language was limited to English. Reviews and case reports were excluded. Different types of studies were included via different criteria.

Prospective studies were included according to the following criteria: i) diagnosis of LM complies with the National Comprehensive Cancer Network (NCCN) guidelines (19); ii) ITC was administered in prospective manner, even if few patients received concurrent systemic chemotherapy; and iii) contains individually assessable information regarding the therapeutic response or survival of NSCLC patients with LM. Finally, 4 prospective studies investigating ITC were included (7,20-22). No control group was set in all 4 studies.

Retrospective studies were included according to the following criteria: i) Diagnosis of LM complies with the NCCN guidelines (19); ii) only analyzed NSCLC patients with LM; and iii) contains comparable information regarding response rate or survival related to ITC. There were 5 retrospective studies analyzing LM from NSCLC that were included $(1,10,12,23,24)$.

Patients. In each prospective study, only the patients diagnosed with LM from NSCLC were pooled for analysis. As the prospective studies did not mention which patients were treated by concurrent systemic chemotherapy, these patients could not be analyzed separately. All patients in the included retrospective studies were analyzed. However, all retrospective studies did not provide the individual information of each patient. Hence, the data of prospective and retrospective studies could not be reorganized.

Reevaluation of therapeutic response. As no standardized criteria for the evaluation of therapeutic response had been defined or universally agreed at the time that the included prospective studies were conducted (16), there were some differences in criteria among these studies. For the feasibility of reevaluating data from different studies, therapeutic responses of each reevaluable patient were graded again via the unified criteria defined in the present study (as follows).

Clinical criteria were defined as follows: Complete response (CR), resolution of all neurological signs; partial response (PR), incomplete resolution of neurological signs; stable disease (SD), no change in clinical signs; progressive disease (PD), worsening of preexisting or new neurological signs. Neuroradiographic criteria were defined as follows: $\mathrm{CR}$, resolution of all neuroradiographic signs; PR, incomplete resolution of neuroradiographic signs; SD, no change in neuroradiographic signs; PD, worsening of preexisting or new neuroradiographic signs. For cytological response, the definitions of CR, PR, SD and PD were difficult to determine because of the variety of original criteria in the included studies. Thus, cytological response was graded only into two levels: With response [improved cerebrospinal fluid (CSF) cytology]; and without response (worsening CSF cytology or no change). Although this grading is simple, it was the optimal option available for the present analysis.

The present clinical and neuroradiographic criteria are the same as the criteria defined by Chamberlain et al (7). As the retrospective studies did not provide individual information, the response rates of these reports were combined only when necessary.

Reevaluation of survival. The time of survival of reevaluable patients was calculated on the basis of the records of each original study. The start point of survival was the onset of LM-directed therapy in prospective studies, and the diagnosis of LM in retrospective studies. The end point of survival was mortality of the patient. If the patient was alive at the end of study, the recorded time was considered to be their overall survival. Survival curves were constructed using the Kaplan-Meier method and SPSS 19.0 software (IBM, Armonk, NY, USA).

Comparison among different studies (groups). As the data of prospective and retrospective studies could not be reorganized, a simple comparison among the included studies was conducted. To do this, these studies were first renumbered via a suitable index: Response rate was used as the numbering index for the comparison of therapeutic response; and median survival was used as the numbering index for the comparison of survival. Then, studies were ranked by this number to compare relevant information.

\section{Results}

Studies. The basic information of the included studies is summarized in Table I. The original eligibility criteria of patients, criteria of diagnosis and evaluation of the included studies are summarized in Tables II, III and IV, respectively.

Patients. According to the eligibility criteria defined in the present study, 69 patients in prospective studies and 520 patients in retrospective studies were pooled for analysis. In detail, 68 patients were reevaluable for analysis of response rate, 50 patients were reevaluable for analysis of survival and 589 patients were available for comparison (Fig. 1). In total, 37 patients received ITC only, and 552 patients received multiple interventions (ITC, whole-brain radiotherapy, EGFR TKI, systemic chemotherapy, and/or support care). The basic information of pooled patients is summarized in Table $\mathrm{V}$, and the individual information of reevaluable patients is listed in Table VI.

Results of reevaluating patients. The cytological, clinical and neuroradiographic response rates were 55\% (53-60\%; $n=49)$, $64 \%(53-79 \% ; n=58)$, and 53\% $(n=32)$, respectively (a response was defined as CR plus PR for clinical and neuroradiological responses). Taking SD into account, the clinical response rate was $100 \%$ when ITC was given by ventriculolumbar perfusion. The median survival time was 6.0 months $(95 \% \mathrm{CI}$, 5.2-6.8; Fig. 2A). The log-rank test calculated a P-value of 0.017 for the three comparable groups.

Results of comparing studies. For comparison of therapeutic response, the studies with available response rates were ranked according to ascending response rate, and then the detailed design of matched regimens was summarized (Table VII). The percentage of symptomatic improvement was markedly higher 


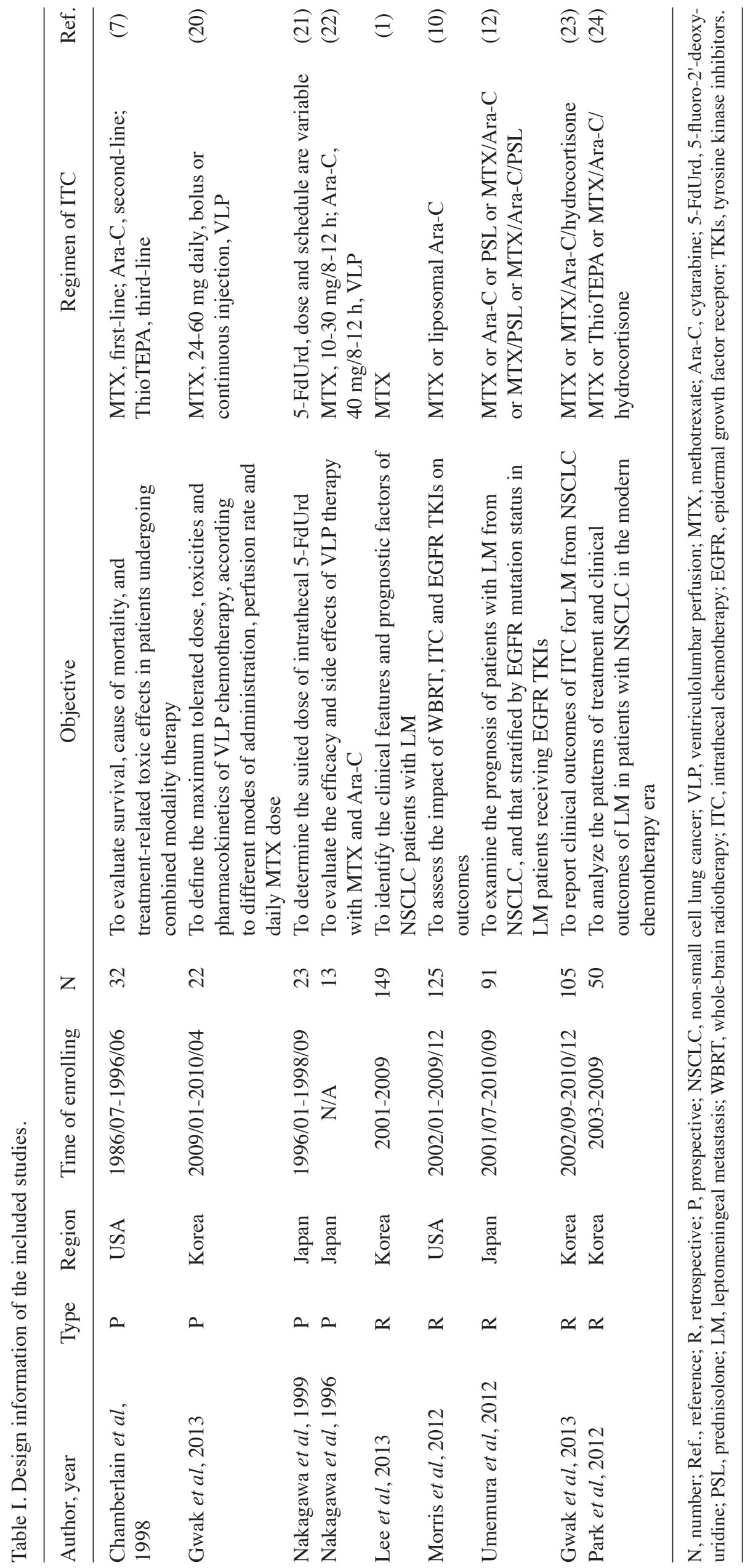




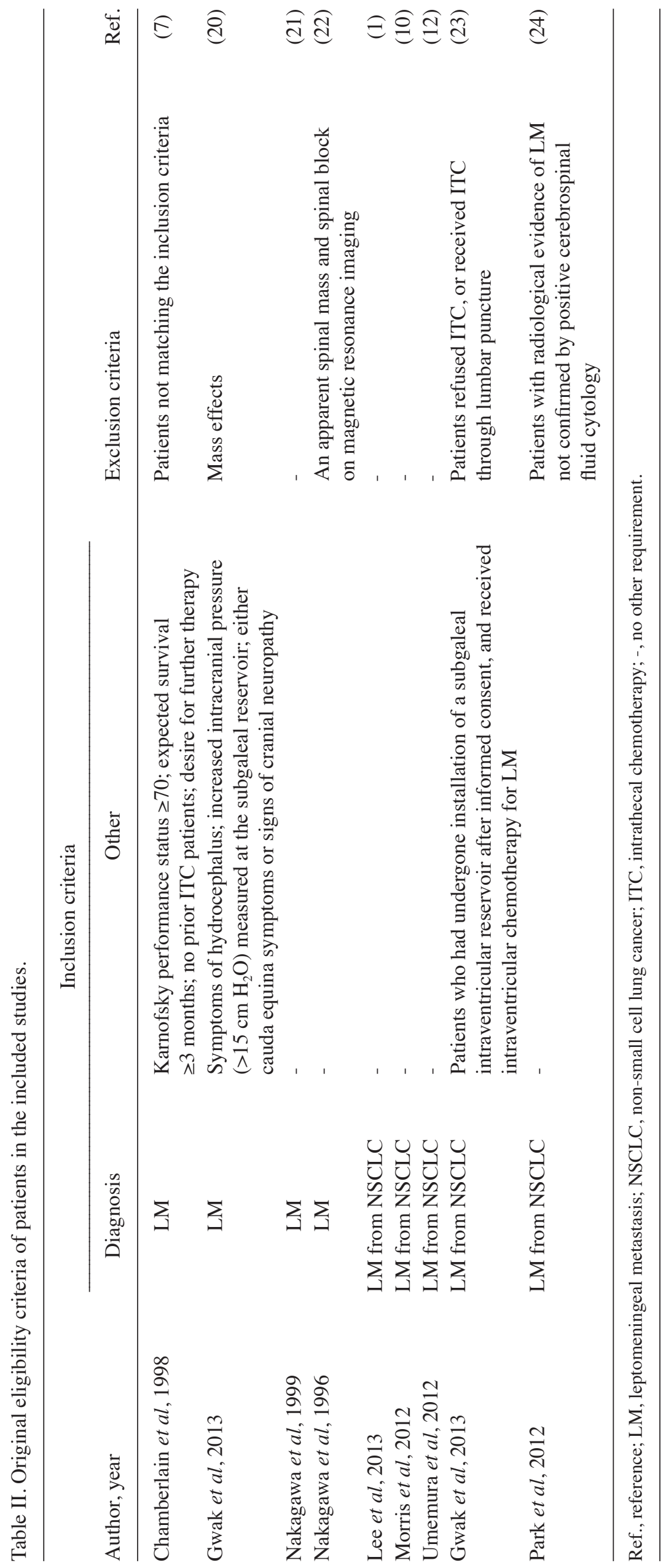




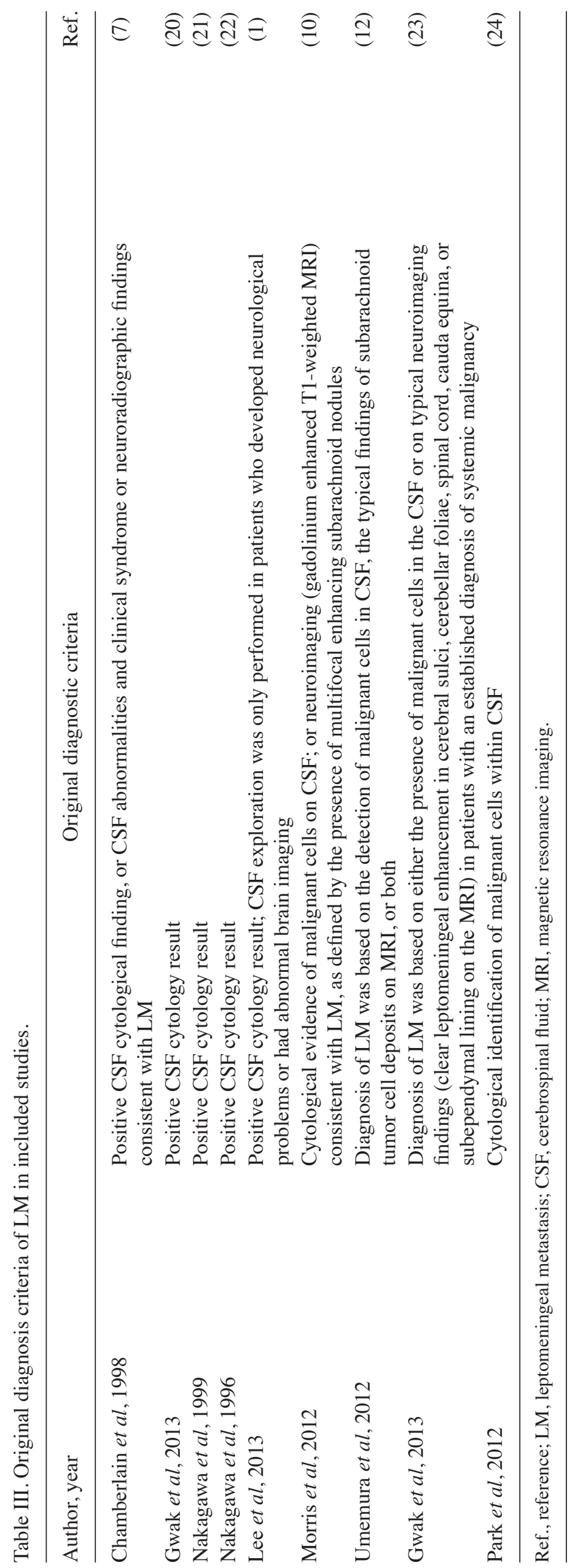




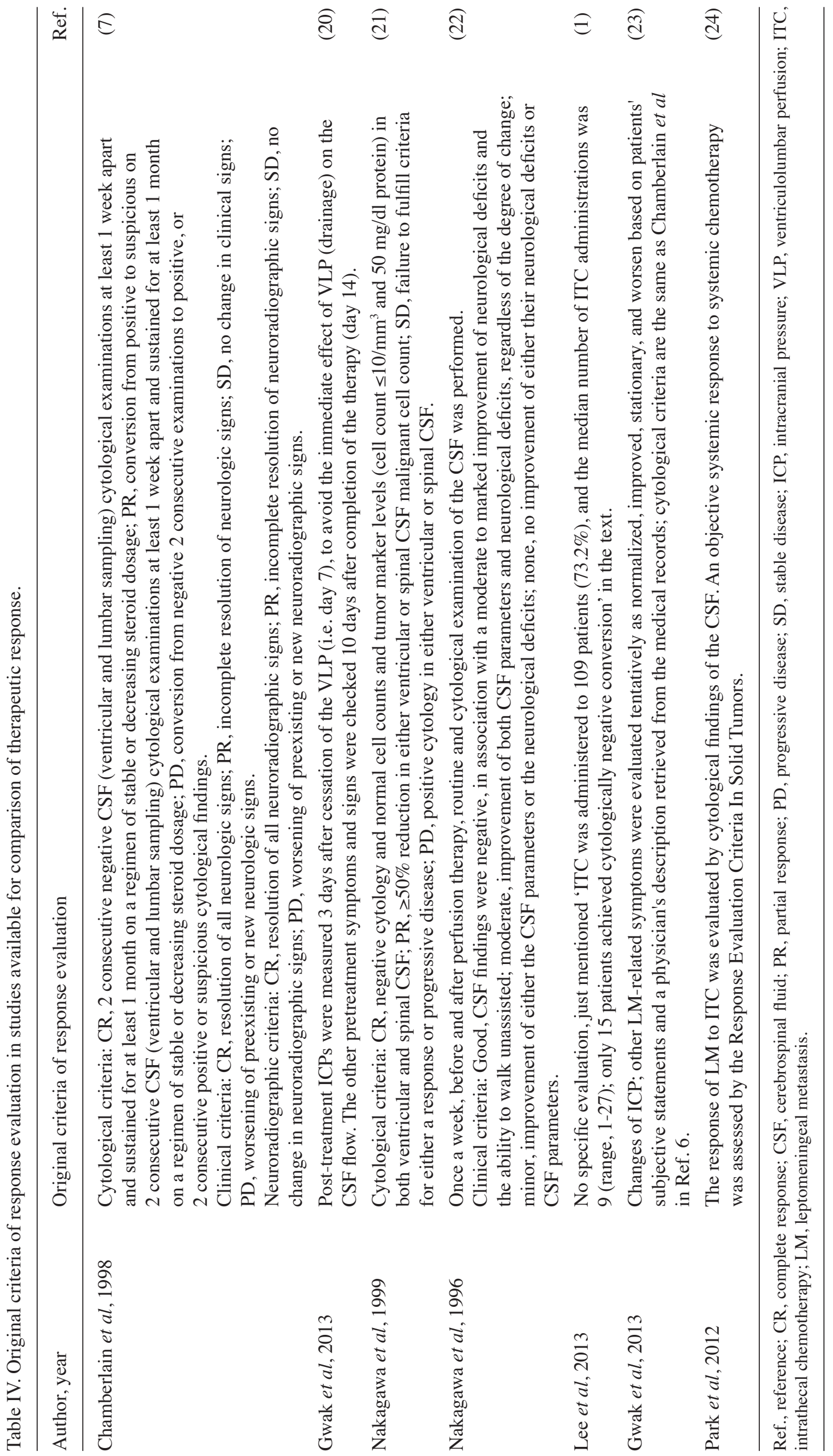


Table V. Patient characteristics (only patients enrolled in the current study) of included studies.

\begin{tabular}{|c|c|c|c|c|c|c|c|c|c|c|}
\hline & \multirow{2}{*}{$\begin{array}{c}\text { Enrolled } \\
\text { patients, } \\
\mathrm{N}\end{array}$} & \multicolumn{4}{|c|}{ Histology (NSCLC) } & \multirow{2}{*}{$\begin{array}{c}\text { Gender } \\
\text { (male/ } \\
\text { female), } \\
\mathrm{N}\end{array}$} & \multirow{2}{*}{$\begin{array}{l}\text { Median } \\
\text { age, years } \\
\text { (range) }\end{array}$} & \multirow{2}{*}{$\begin{array}{l}\text { Median } \\
\text { KPS } \\
\text { (range) }\end{array}$} & \multirow{2}{*}{$\begin{array}{l}\text { Patients } \\
\text { with a } \\
\text { poor } \\
\text { PS }^{\text {a }}(\%)\end{array}$} & \multirow[b]{2}{*}{ Ref. } \\
\hline & & $\mathrm{AD}$ & $\mathrm{LCC}$ & SQ & Other & & & & & \\
\hline Chamberlain et al, 1998 & 32 & 24 & 6 & 2 & 0 & $22 / 10$ & $57(48-73)$ & $90(70-100)$ & 0 & $(7)$ \\
\hline Gwak et al, 2013 & 19 & 18 & 1 & 0 & 0 & $7 / 12$ & $52(37-67)$ & $60(40-90)$ & 47.4 & $(20)$ \\
\hline Nakagawa et al, 1999 & 11 & 11 & 0 & 0 & 0 & $3 / 8$ & $59(48-73)$ & $-\mathrm{b}$ & $-{ }^{b}$ & $(21)$ \\
\hline Nakagawa et al, 1996 & 7 & 5 & 1 & 1 & 0 & $2 / 5$ & $52(44-57)$ & - & 71.4 & $(22)$ \\
\hline Lee et al, 2013 & 149 & 135 & - & - & 14 & $76 / 73$ & $58(34-80)$ & - & 13.4 & (1) \\
\hline Morris et al, 2012 & 125 & 97 & 2 & 4 & 22 & $45 / 80$ & $59(28-87)$ & $70(30-100)$ & - & $(10)$ \\
\hline Umemura et al, 2012 & 91 & 83 & 2 & 2 & 4 & $47 / 44$ & $62(35-79)$ & - & 42.9 & (12) \\
\hline Gwak et al, 2013 & 105 & 101 & 2 & 2 & 0 & $44 / 61$ & $56(31-75)$ & $70(40-90)$ & 47.6 & $(23)$ \\
\hline Park et al, 2012 & 50 & 42 & - & 3 & 5 & $25 / 25$ & $62.5(34-81)$ & - & 30.0 & (24) \\
\hline
\end{tabular}

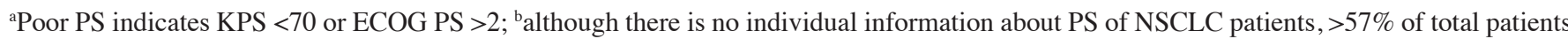
had a poor PS (KPS $<70$ or ECOG PS >2) in Ref. 21. N, number; NSCLC, non-small cell lung cancer; AD, adenocarcinoma; LCC, large cell carcinoma; SQ, squamous cell carcinoma; KPS, Karnofsky performance status; PS, performance status; Ref., reference; -, unavailable; ECOG, Eastern Cooperative Oncology Group.

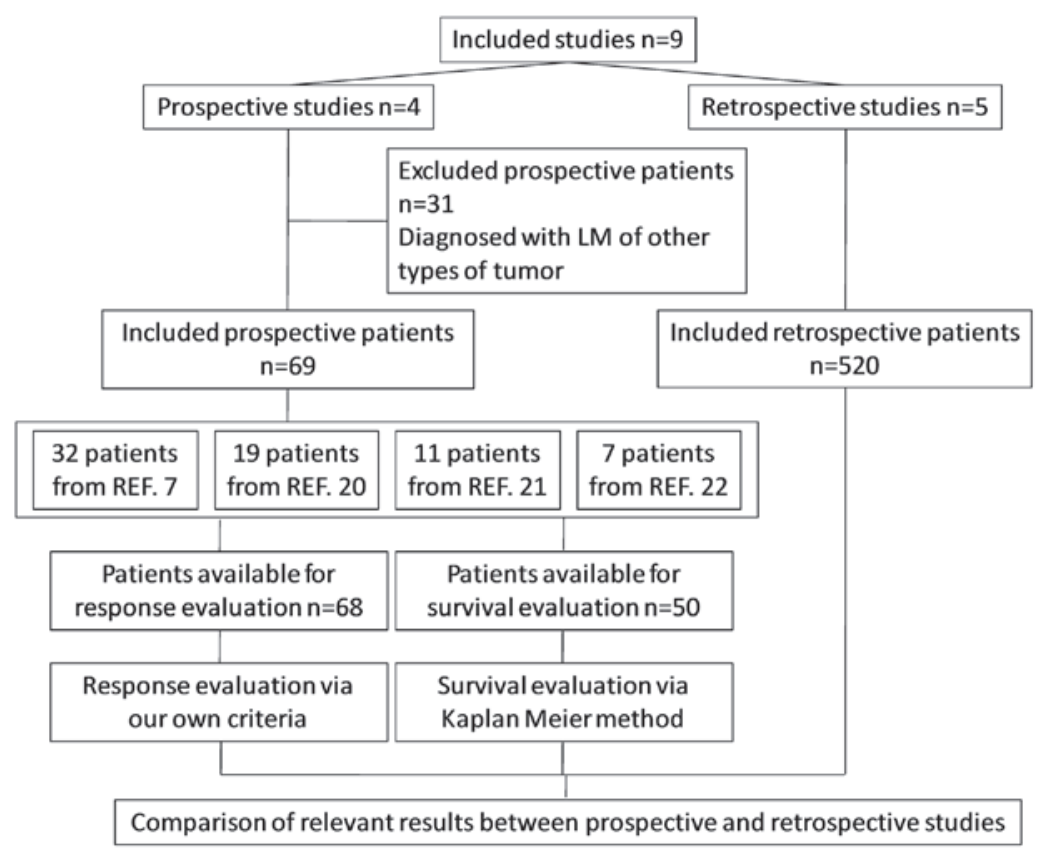

Figure 1. Flow diagram. REF, reference.

in studies in which the patients received ITC only $(20,22)$. If SD is taken into account, the clinical response rate was $100 \%$ in these studies. Notably, the majority of the patients in these particular studies had a poor performance status (PS) (Table V). These results reveal that ITC with a suitable regimen may offer a promising response rate, particularly for the improvement of clinical symptoms.

All matched survival information of the analyzed patients in different studies is illustrated in Fig. 2B. The total and ITC-related median survival times of pooled patients were all $>2$ months (range, 3.0-18.0 months). Notably, all of the total median survival times of patients receiving multiple interventions $(3.0-5.0$ months) $(1,7,10,12,23,24)$ have a narrower range and are shorter than that of patients receiving ITC only (7.5 months) $(21,22)$. Furthermore, the start point of survival in patients receiving ITC only is later than that in patients receiving multiple interventions. Additionally, the percentages of each intervention among the different studies were evidently different.

LM patients with poor PS have a poor prognosis (19). However, in the study with the highest percentage of patients having poor PS (Table II), the median survival time was the longest (8.0 months) (22). These results indicate that ITC may offer survival benefits under a suitable regimen. However, the shorter median survival time and narrower range of patients 
Table VI. The individual information of enrolled prospective patients.

\begin{tabular}{|c|c|c|c|c|c|c|c|}
\hline & \multicolumn{2}{|c|}{ Patient no. } & \multirow{2}{*}{$\begin{array}{l}\text { Age, } \\
\text { years }\end{array}$} & \multirow[b]{2}{*}{ Gender } & \multicolumn{2}{|c|}{ Data available for } & \multirow[b]{2}{*}{ Ref. } \\
\hline & New & Original & & & Response & Survival & \\
\hline \multirow[t]{32}{*}{ Chamberlain et al, 1998} & 1 & 1 & 49 & $22 \mathrm{M} / 10 \mathrm{~F}$ & $\mathrm{Y}$ & $\mathrm{Y}$ & (7) \\
\hline & 2 & 2 & 63 & & $\mathrm{Y}$ & $\mathrm{Y}$ & \\
\hline & 3 & 3 & 61 & & $\mathrm{Y}$ & $\mathrm{Y}$ & \\
\hline & 4 & 4 & 58 & & $\mathrm{Y}$ & $\mathrm{Y}$ & \\
\hline & 5 & 5 & 60 & & $\mathrm{Y}$ & $\mathrm{Y}$ & \\
\hline & 6 & 6 & 73 & & $\mathrm{Y}$ & $\mathrm{Y}$ & \\
\hline & 7 & 7 & 59 & & $\mathrm{Y}$ & $\mathrm{Y}$ & \\
\hline & 8 & 8 & 62 & & $\mathrm{Y}$ & $\mathrm{Y}$ & \\
\hline & 9 & 9 & 56 & & $\mathrm{Y}$ & $\mathrm{Y}$ & \\
\hline & 10 & 10 & 58 & & $\mathrm{Y}$ & $\mathrm{Y}$ & \\
\hline & 11 & 11 & 60 & & $\mathrm{Y}$ & $\mathrm{Y}$ & \\
\hline & 12 & 12 & 62 & & $\mathrm{Y}$ & $\mathrm{Y}$ & \\
\hline & 13 & 13 & 61 & & $\mathrm{Y}$ & $\mathrm{Y}$ & \\
\hline & 14 & 14 & 58 & & $\mathrm{Y}$ & $\mathrm{Y}$ & \\
\hline & 15 & 15 & 54 & & $\mathrm{Y}$ & $\mathrm{Y}$ & \\
\hline & 16 & 16 & 56 & & $\mathrm{Y}$ & $\mathrm{Y}$ & \\
\hline & 17 & 17 & 62 & & $\mathrm{Y}$ & $\mathrm{Y}$ & \\
\hline & 18 & 18 & 65 & & $\mathrm{Y}$ & $\mathrm{Y}$ & \\
\hline & 19 & 19 & 52 & & $\mathrm{Y}$ & $\mathrm{Y}$ & \\
\hline & 20 & 20 & 49 & & $\mathrm{Y}$ & $\mathrm{Y}$ & \\
\hline & 21 & 21 & 61 & & $\mathrm{Y}$ & $\mathrm{Y}$ & \\
\hline & 22 & 22 & 60 & & $\mathrm{Y}$ & $\mathrm{Y}$ & \\
\hline & 23 & 23 & 58 & & $\mathrm{Y}$ & $\mathrm{Y}$ & \\
\hline & 24 & 24 & 56 & & $\mathrm{Y}$ & $\mathrm{Y}$ & \\
\hline & 25 & 25 & 54 & & $\mathrm{Y}$ & $\mathrm{Y}$ & \\
\hline & 26 & 26 & 62 & & $\mathrm{Y}$ & $\mathrm{Y}$ & \\
\hline & 27 & 27 & 48 & & $\mathrm{Y}$ & $\mathrm{Y}$ & \\
\hline & 28 & 28 & 51 & & $\mathrm{Y}$ & $\mathrm{Y}$ & \\
\hline & 29 & 29 & 62 & & $\mathrm{Y}$ & $\mathrm{Y}$ & \\
\hline & 30 & 30 & 49 & & $\mathrm{Y}$ & $\mathrm{Y}$ & \\
\hline & 31 & 31 & 51 & & $\mathrm{Y}$ & $\mathrm{Y}$ & \\
\hline & 32 & 32 & 56 & & $\mathrm{Y}$ & $\mathrm{Y}$ & \\
\hline \multirow[t]{19}{*}{ Gwak et al, 2013} & 33 & 1 & 53 & $\mathrm{M}$ & $\mathrm{Y}$ & $\mathrm{N}$ & $(20)$ \\
\hline & 34 & 2 & 63 & $\mathrm{M}$ & $\mathrm{Y}$ & $\mathrm{N}$ & \\
\hline & 35 & 3 & 45 & $\mathrm{M}$ & $\mathrm{Y}$ & $\mathrm{N}$ & \\
\hline & 36 & 4 & 45 & M & $\mathrm{Y}$ & $\mathrm{N}$ & \\
\hline & 37 & 5 & 45 & M & $\mathrm{Y}$ & $\mathrm{N}$ & \\
\hline & 38 & 7 & 52 & $\mathrm{M}$ & $\mathrm{Y}$ & $\mathrm{N}$ & \\
\hline & 39 & 8 & 49 & $\mathrm{~F}$ & $\mathrm{Y}$ & $\mathrm{N}$ & \\
\hline & 40 & 9 & 50 & $\mathrm{~F}$ & $\mathrm{Y}$ & $\mathrm{N}$ & \\
\hline & 41 & 11 & 37 & $\mathrm{~F}$ & $\mathrm{Y}$ & $\mathrm{N}$ & \\
\hline & 42 & 12 & 62 & $\mathrm{~F}$ & $\mathrm{Y}$ & $\mathrm{N}$ & \\
\hline & 43 & 13 & 49 & $\mathrm{~F}$ & $\mathrm{Y}$ & $\mathrm{N}$ & \\
\hline & 44 & 14 & 49 & $\mathrm{~F}$ & $\mathrm{Y}$ & $\mathrm{N}$ & \\
\hline & 45 & 16 & 67 & $\mathrm{~F}$ & $\mathrm{Y}$ & $\mathrm{N}$ & \\
\hline & 46 & 17 & 67 & $\mathrm{~F}$ & $\mathrm{Y}$ & $\mathrm{N}$ & \\
\hline & 47 & 18 & 62 & $\mathrm{M}$ & $\mathrm{Y}$ & $\mathrm{N}$ & \\
\hline & 48 & 19 & 52 & $\mathrm{~F}$ & $\mathrm{Y}$ & $\mathrm{N}$ & \\
\hline & 49 & 20 & 56 & $\mathrm{~F}$ & $\mathrm{Y}$ & $\mathrm{N}$ & \\
\hline & 50 & 21 & 51 & $\mathrm{~F}$ & $\mathrm{Y}$ & $\mathrm{N}$ & \\
\hline & 51 & 22 & 42 & $\mathrm{~F}$ & Y & $\mathrm{N}$ & \\
\hline \multirow[t]{3}{*}{ Nakagawa et al, 1999} & 52 & 1 & 63 & $\mathrm{~F}$ & $\mathrm{Y}$ & $\mathrm{Y}$ & $(21)$ \\
\hline & 53 & 2 & 65 & $\mathrm{~F}$ & $\mathrm{~N}$ & $\mathrm{Y}$ & \\
\hline & 54 & 3 & 49 & $\mathrm{~F}$ & $\mathrm{Y}$ & $\mathrm{Y}$ & \\
\hline
\end{tabular}


Table VI. Continued.

\begin{tabular}{|c|c|c|c|c|c|c|c|}
\hline \multirow[b]{2}{*}{ Author, year } & \multicolumn{2}{|c|}{ Patient no. } & \multirow{2}{*}{$\begin{array}{l}\text { Age, } \\
\text { years }\end{array}$} & \multirow[b]{2}{*}{ Gender } & \multicolumn{2}{|c|}{ Available for } & \multirow[b]{2}{*}{ Ref. } \\
\hline & New & Original & & & Response & Survival & \\
\hline \multirow[t]{8}{*}{ Nakagawa et al, 1999} & 55 & 4 & 56 & $\mathrm{~F}$ & $\mathrm{Y}$ & $\mathrm{Y}$ & \multirow[t]{8}{*}{ (21) } \\
\hline & 56 & 7 & 48 & F & Y & Y & \\
\hline & 57 & 8 & 70 & M & Y & $\mathrm{Y}$ & \\
\hline & 58 & 18 & 53 & $\mathrm{~F}$ & Y & Y & \\
\hline & 59 & 19 & 57 & $\mathrm{~F}$ & Y & Y & \\
\hline & 60 & 20 & 58 & F & Y & Y & \\
\hline & 61 & 21 & 73 & $\mathrm{M}$ & $\mathrm{Y}$ & Y & \\
\hline & 62 & 22 & 63 & M & $\mathrm{Y}$ & $\mathrm{Y}$ & \\
\hline \multirow[t]{7}{*}{ Nakagawa et al, 1996} & 63 & 1 & 54 & $\mathrm{~F}$ & $\mathrm{Y}$ & $\mathrm{Y}$ & \multirow[t]{7}{*}{ (22) } \\
\hline & 64 & 2 & 57 & M & $\mathrm{Y}$ & $\mathrm{Y}$ & \\
\hline & 65 & 3 & 49 & $\mathrm{~F}$ & $\mathrm{Y}$ & $\mathrm{Y}$ & \\
\hline & 66 & 8 & 54 & F & Y & Y & \\
\hline & 67 & 10 & 51 & $\mathrm{~F}$ & $\mathrm{Y}$ & $\mathrm{Y}$ & \\
\hline & 68 & 11 & 56 & $\mathrm{~F}$ & $\mathrm{Y}$ & $\mathrm{Y}$ & \\
\hline & 69 & 12 & 44 & M & $\mathrm{Y}$ & $\mathrm{Y}$ & \\
\hline Total & 69 & & & & 68 & 50 & \\
\hline
\end{tabular}

Ref., reference; M, male; F, female; Y, yes; N, no.

receiving multiple interventions is not associated with poor prognosis, as these patients had better PS (Table V).

All of the retrospective studies included patients enrolled between 2000 and 2010 (Table I). Only two studies $(23,24)$ excluded some of the patients according to their eligibility criteria (Table II). Furthermore, the regimens of ITC among the retrospective studies were also similar (Tables I and VII). However, the studies involving multiple interventions had significant heterogeneity with regard to numerous characteristics, such as race and the percentages of patients with poor PS and ITC (Tables I and V; Fig. 3). Additionally, the differences in the percentages of patients with poor PS and receiving ITC cannot explain the differences in median survival time among the studies involving multiple interventions. Hence, there must be other important factors causing the shortening median survival time and narrowing of the range in patients receiving multiple interventions.

For better understanding, the studies with available survival information were ranked according to the ascending order of the median survival time values (Table VIII). The matched percentage of patients receiving each intervention was also calculated and listed in Table VIII. Notably, the significant shortening of median survival time was accompanied by a high percentage of patients receiving multiple interventions. The effect was enhanced when the interventions were given concurrently. These results suggest that the shortening of median survival time and narrowing of the range were caused by the reduction of body tolerance during repeated treatments, and also the aggravation of side effects during combination therapy.

Bias. The current study is a pooled analysis. All the data of patients came from published studies. Selection and publication biases must be considered. Without any doubt, these biases would be overcome via an RCT. However, the extremely low incidence of LM makes the implementation of RCTs very challenge and time-consuming. Prior to the publication of any convincing RCTs, the current study indeed offers some suggestions for clinical practice.

\section{Discussion}

The current study presented a pooled analysis including the largest number of NSCLC patients with LM. Although many prospective studies have been conducted to investigate drug therapy for LM from solid tumors (including NSCLC) $(6,25-37)$, they were not available according to the criteria defined in the current study. However, these studies still offer useful information for selecting suitable experimental drugs and regimens in clinical trials that are aiming to investigate ITC for the treatment of NSCLC patients with LM (Table IX).

As there was no individually assessable information, it was not possible to reevaluate side effects that occurred in evaluable patients. According to the reporting of each study, the incidence of side effects was low, and the symptoms were mild, usually manifesting as slight headache, nausea and fever. There was an increasing trend in the incidence of side effects in patients receiving more treatments (7).

Compared with each study, higher response rates are achieved under suited regimen, particularly under relatively intensive regimens (e.g., more drug types, higher doses or longer administration time; Table VII). Although the higher response rates were predominantly reported by studies with relative small sample sizes, the low rates reported in the two 


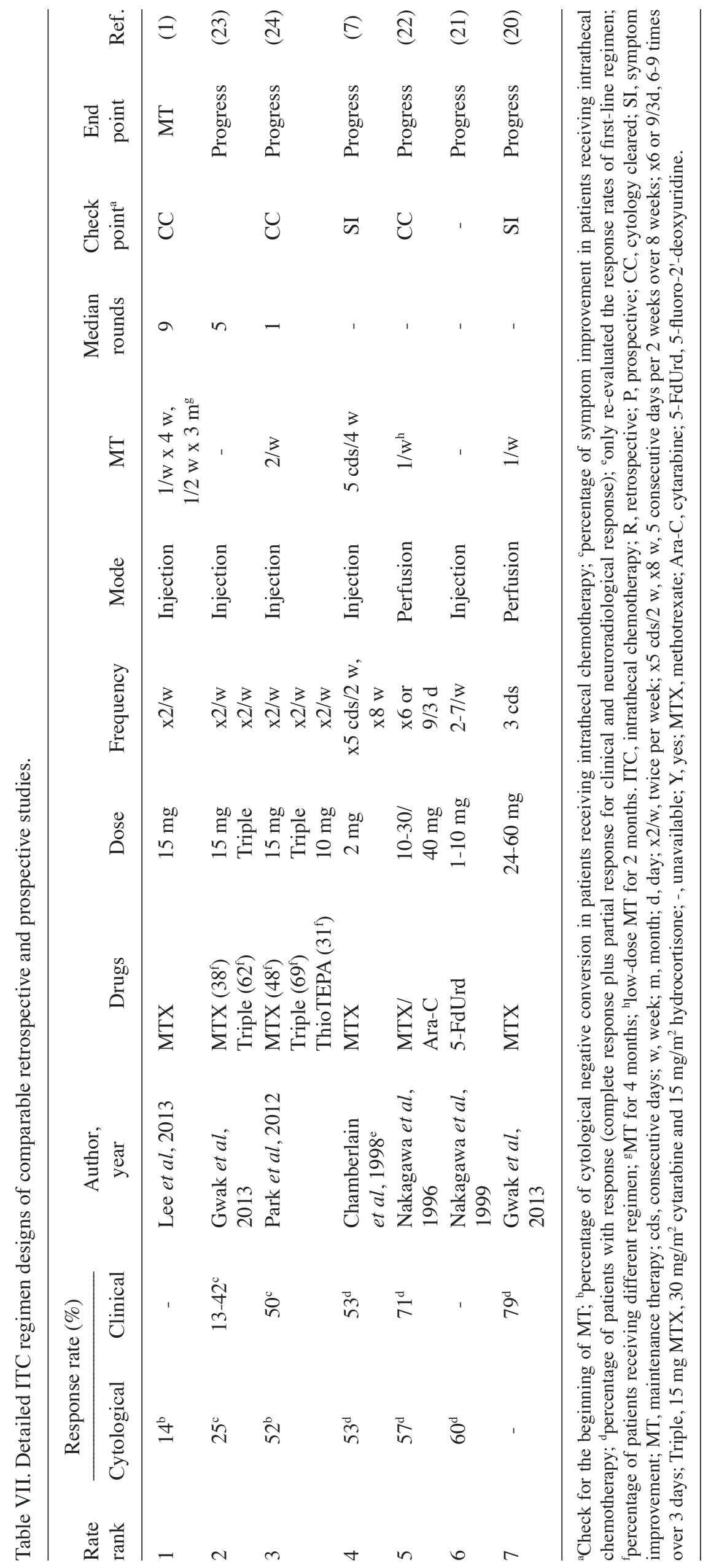


Table VIII. Percentages of intervention in included studies.

\begin{tabular}{|c|c|c|c|c|c|c|c|c|c|}
\hline $\begin{array}{l}\text { MS } \\
\text { rank }\end{array}$ & $\begin{array}{c}\mathrm{MS} \\
\mathrm{mOS}\end{array}$ & mOS-ITC & Author, year & ITC $(\%)$ & TKI $(\%)$ & $\operatorname{SCT}(\%)$ & WBRT (\%) & $\mathrm{SC}(\%)$ & Ref. \\
\hline 1 & $3.0 \mathrm{mo}$ & $3.0 \mathrm{mo}$ & Gwak et al, 2013 & 100.0 & $27.6^{\mathrm{c}}$ & $22.9^{c}$ & $28.6^{c}$ & - & $(23)$ \\
\hline 2 & $3.0 \mathrm{mo}$ & $18.0 \mathrm{mo}^{\mathrm{a}}$ & Morris et al, 2012 & 6.0 & 14.0 & 16.0 & 45.0 & 30.0 & $(10)$ \\
\hline 3 & 14 wks & 17 wks & Lee et $a l, 2013$ & 73.2 & 16.1 & 16.8 & 43.7 & 13.4 & (1) \\
\hline 4 & $3.6 \mathrm{mo}$ & - & Umemura et al, 2012 & 29.7 & 56.0 & 29.9 & 23.1 & 25.3 & $(12)$ \\
\hline 5 & $4.3 \mathrm{mo}$ & - & Park et al, 2012 & 96.0 & 28.0 & 24.0 & $42.2^{\mathrm{c}}$ & - & $(24)$ \\
\hline 6 & $5.0 \mathrm{mo}$ & $5.0 \mathrm{mo}$ & Chamberlain et al, 1998 & 100.0 & 0.0 & $37.5^{\mathrm{c}}$ & $28.1^{\mathrm{d}}$ & 0.0 & (7) \\
\hline 7 & $6.0 \mathrm{mo}$ & $6.0 \mathrm{mo}$ & Present study & 100.0 & 0.0 & $24.0^{\mathrm{c}}$ & $18.0^{\mathrm{d}}$ & 0.0 & \\
\hline 8 & $7.0 \mathrm{mo}$ & $7.0 \mathrm{mo}$ & Nakagawa et al, $1999^{b}$ & 100.0 & 0.0 & $0.0^{\mathrm{e}}$ & $0.0^{\mathrm{e}}$ & 0.0 & $(21)$ \\
\hline 9 & $7.5 \mathrm{mo}$ & $7.5 \mathrm{mo}$ & Present study ${ }^{\mathrm{c}}$ & 100.0 & 0.0 & $0.0^{\mathrm{e}}$ & $0.0^{\mathrm{e}}$ & 0.0 & \\
\hline 10 & $8.0 \mathrm{mo}$ & $8.0 \mathrm{mo}$ & Nakagawa et al, $1996^{\mathrm{b}}$ & 100.0 & 0.0 & 0.0 & 0.0 & 0.0 & (22) \\
\hline
\end{tabular}

${ }^{\mathrm{a} O n l y} 6$ patients received ITC; ${ }^{\mathrm{b}}$ Also calculated in the present study; ${ }^{\mathrm{c}}$ concurrent with ITC; ${ }^{\mathrm{d}}$ prior to ITC; ${ }^{\mathrm{e}}$ Some patients in this study received WBRT or SCT prior to ITC, but the start point for calculating survival is the onset of ITC. MS, median survival; mOS, MS of all the patients; mOS-ITC, MS related to ITC; ITC, intrathecal chemotherapy; SCT, systemic chemotherapy; WBRT, whole-brain radiotherapy; SC, support care; Ref., reference; mo, months; wks, weeks; -, unavailable.
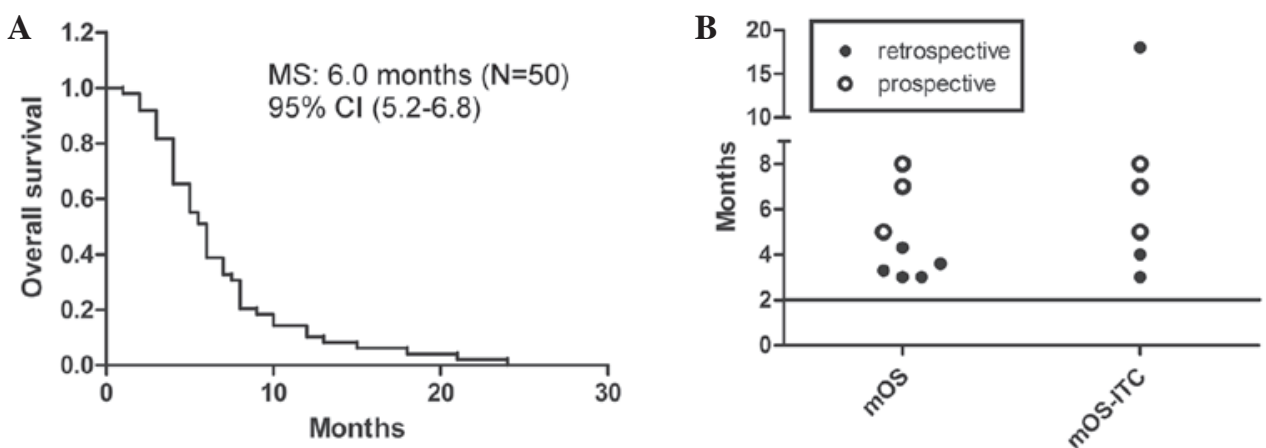

Figure 2. Survival of enrolled patients. (A) MS of eligible prospective patients. (B) MS of included studies. Line indicates MS of patients without treatments. MS, median survival; CI, confidence interval; mOS, median overall survival; mOS-ITC, median overall survival related to intrathecal chemotherapy.

retrospective studies with a large sample number $(1,23)$ still support the need for relatively intensive regimens. Considering patients also received other kinds of interventions when necessary (prior to enrolling in the original clinical trial), we speculate that the need for relatively intensive regimen is determined by the biological features of NSCLC or the drug tolerance induced by repeated treatments. As the reported side effects are slight, and serious side effects are rare, it is worth trying relatively intensive regimens in patients who are able to tolerate it well. In fact, Nakagawa et al (21) attempted to determine patient tolerance by daily dose and weekly dosage schedule, in order to achieve better efficacy.

The median survival times of pooled patients were all $>2$ months. Notably, in patients treated predominantly by ITC, the longest median survival time was observed (6.0 months). This may be explained by the type of patients pooled in the current analysis: Clinical trials reporting shorter median survival times usually enrolled patients with different types of tumor to expand the sample size (Table IX) (38).

Tolerance is one of the important factors that requires consideration when multiple interventions are administered to a patient. LM from NSCLC indicates the end-stage of disease

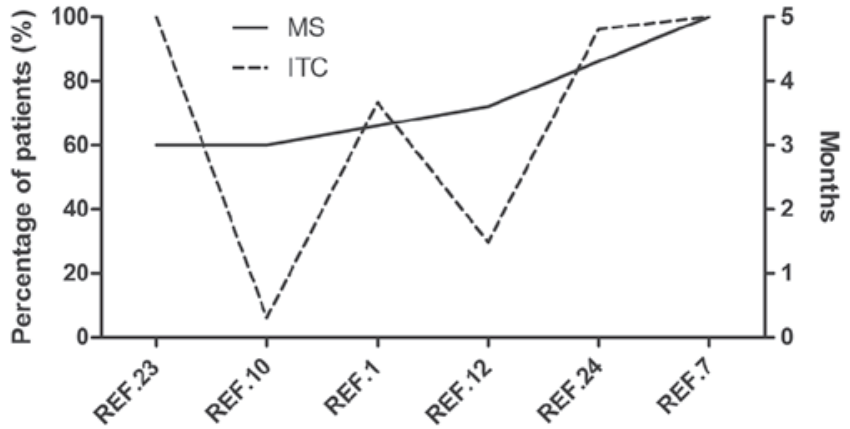

Figure 3. MS and percentage of ITC in included retrospective studies. MS, median survival; ITC, intrathecal chemotherapy; REF., reference.

that is usually associated with poor PS and low body tolerance. Thus, suitable combination strategies of multidisciplinary therapy are extremely important for NSCLC patients with LM. Besides the studies included in the current analysis, other authors also retrospectively reported that the median survival time of 30 NSCLC patients with LM was 6.0 months, with $53 \%$ of patients receiving modern systemic therapy defined as 


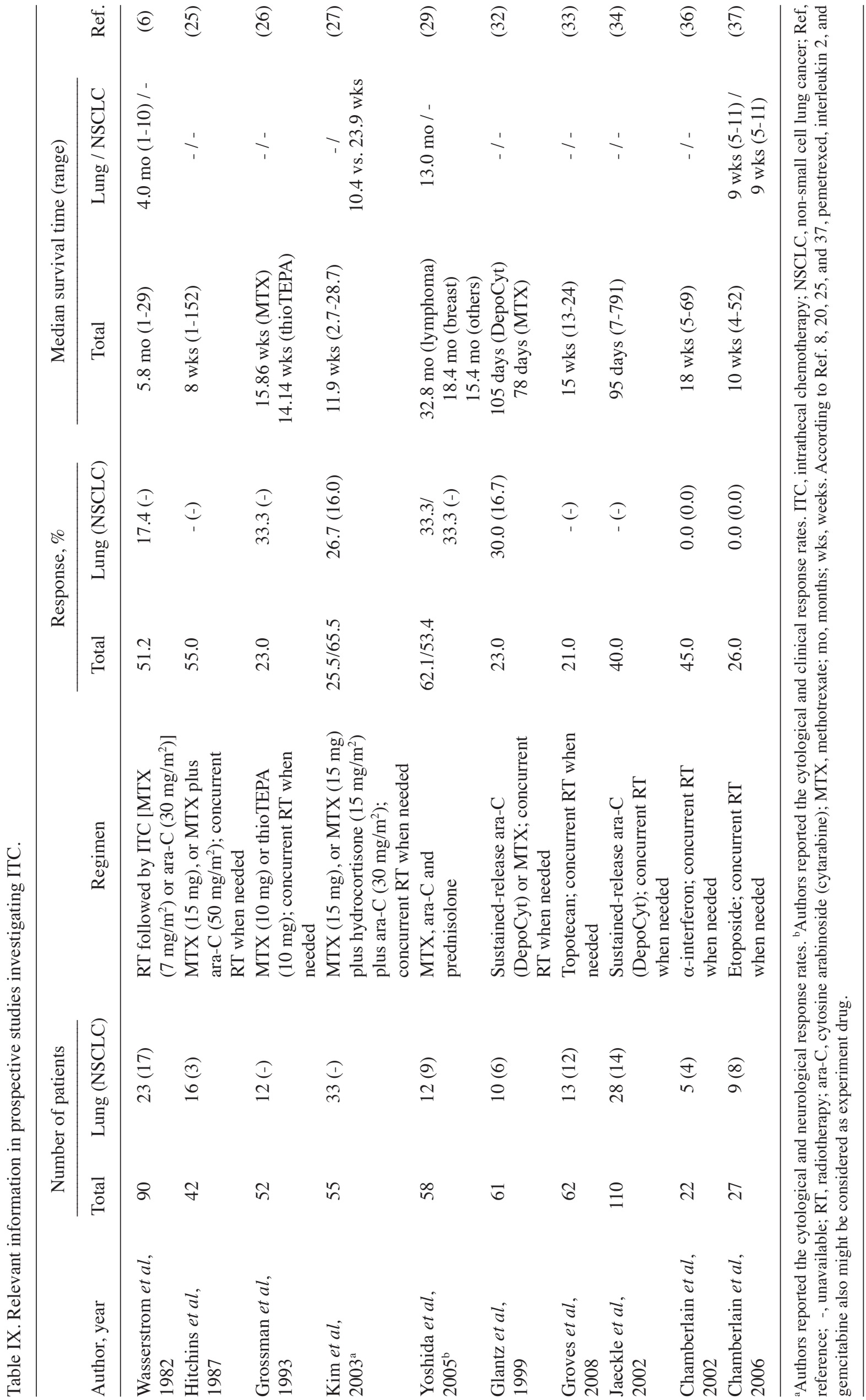


a regimen containing pemetrexed, bevacizumab or a TKI (39). Another two Phase II clinical trials also reported that lung cancer patients receiving concurrent ITC and radiotherapy [ 3 out of 5 patients (36) and 7 out of 8 patients (37)] exhibited short survival times without response $(36,37)$. The indication for radiotherapy in such patients must be better defined, considering that WBRT does not appear to contribute to survival $(3,10)$.

EGFR TKI treatment is also considered to be a significant intervention, particularly to patients with sensitive mutations $(1,11-13,23,24)$. Although it was reported that EGFR TKI offered higher response rate (14) and longer survival time (12) compared with other interventions, the studies $(12,14)$ are still retrospective and has a smaller patient number. Meanwhile, the selectivity of EGFR TKI treatment limits the scope of application, and patients are increasingly administered EGFR TKI treatment prior to the diagnosis of LM, which can lead to the development of drug tolerance. Incomplete penetration of the drug is considered to be one of the reasons for treatment failure (40-42). Although erlotinib exhibits improved capability of penetration (43) and disease control (14) compared with other EGFR TKIs, ITC remains a more direct, less selective and also well tolerated method of treatment. As the status of EGFR mutation is not clear for all of the pooled patients, it is not possible to compare the two interventions in the current study. Future clinical studies should perform a comparison between ITC and EGFR TKI treatment.

Recently, experts in LM developed a consensus proposal [Response Assessment in Neuro-Oncology (RANO) criteria] for evaluating the response to treatment of patients with LM (44), considering the lack of standardization and the importance of criteria for future clinical trials (38). Unfortunately, this new criteria was not practicable in the current study. If the new criteria are used, ITC may not offer such promising response rate, as the new criteria pay more attention to the cytological and radiographic responses. However, in NSCLC patients with LM, survival is the most important indicator of response evaluation, based on the analyzed results of median survival time. In other words, symptomatic improvement is the main target for the treatment of LM in patients with poor prognosis. This must be considered during the design of future clinical trials, and investigators must also consider the feasibility of the new RANO criteria in patients with varying prognoses.

In summary, for NSCLC patients with LM, ITC may offer promising response rates and survival benefits under suitable regimen. A suitable combination strategy of multidisciplinary therapy is important to NSCLC patients with LM.

\section{Acknowledgements}

The authors greatly appreciate the valuable comments and helpful assistance of Dr Kehong Zhang (The Ivy Editing, Shanghai, China) in preparing the manuscript.

\section{References}

1. Lee SJ, Lee JI, Nam DH, Ahn YC, Han JH, Sun JM, Ahn JS, Park $\mathrm{K}$ and Ahn MJ: Leptomeningeal carcinomatosis in non-small-cell lung cancer patients: Impact on survival and correlated prognostic factors. J Thorac Oncol 8: 185-191, 2013.
2. Christoph DC and Reckamp KL: Intraventricular chemotherapy for leptomeningeal carcinomatosis from lung cancer: A feasible and beneficial treatment option? J Thorac Oncol 8: 523-524, 2013.

3. Nagpal S, Riess J and Wakelee H: Treatment of leptomeningeal spread of NSCLC: A continuing challenge. Curr Treat Options Oncol 13: 491-504, 2012.

4. Waki F, Ando M, Takashima A, Yonemori K, Nokihara H, Miyake M, Tateishi U, Tsuta K, Shimada Y, Fujiwara Y and Tamura T: Prognostic factors and clinical outcomes in patients with leptomeningeal metastasis from solid tumors. J Neurooncol 93: 205-212, 2009.

5. Hustu HO, Aur RJ, Verzosa MS, Simone JV and Pinkel D: Prevention of central nervous system leukemia by irradiation. Cancer 32: 585-597, 1973

6. Wasserstrom WR, Glass JP and Posner JB: Diagnosis and treatment of leptomeningeal metastases from solid tumors: Experience with 90 patients. Cancer 49: 759-772, 1982.

7. Chamberlain MC and Kormanik P: Carcinoma meningitis secondary to non-small cell lung cancer: Combined modality therapy. Arch Neurol 55: 506-512, 1998.

8. Liaw CC, Ng KT, Huang JS, Wang CH, Kiu MC and Lai GM: Meningeal carcinomatosis from solid tumors: Clinical analysis of 42 cases. J Formos Med Assoc 91: 299-303, 1992.

9. Taillibert S and Hildebrand J: Treatment of central nervous system metastases: Parenchymal, epidural, and leptomeningeal. Curr Opin Oncol 18: 637-643, 2006.

10. Morris PG, Reiner AS, Szenberg OR, Clarke JL, Panageas KS, Perez HR, Kris MG, Chan TA, DeAngelis LM and Omuro AM: Leptomeningeal metastasis from non-small cell lung cancer: Survival and the impact of whole brain radiotherapy. J Thorac Oncol 7: 382-385, 2012.

11. Yi HG, Kim HJ, Kim YJ, Han SW, Oh DY, Lee SH, Kim DW, Im SA, Kim TY, Kim CS, et al: Epidermal growth factor receptor (EGFR) tyrosine kinase inhibitors (TKIs) are effective for leptomeningeal metastasis from non-small cell lung cancer patients with sensitive EGFR mutation or other predictive factors of good response for EGFR TKI. Lung Cancer 65: 80-84, 2009.

12. Umemura S, Tsubouchi K, Yoshioka H, Hotta K, Takigawa N, Fujiwara K, Horita N, Segawa Y, Hamada N, Takata I, et al: Clinical outcome in patients with leptomeningeal metastasis from non-small cell lung cancer: Okayama lung cancer study group. Lung Cancer 77: 134-139, 2012.

13. Nakamura Y, Takahashi T, Tsuya A, Naito T, Kenmotsu H, Ono A, Shukuya T, Murakami H, Harada H, Watanabe R, et al: Prognostic factors and clinical outcome of patients with lung adenocarcinoma with carcinomatous meningitis. Anticancer Res 32: 1811-1816, 2012.

14. Lee E, Keam B, Kim DW, Kim TM, Lee SH, Chung DH and Heo DS: Erlotinib versus gefitinib for control of leptomeningeal carcinomatosis in non-small-cell lung cancer. J Thorac Oncol 8: 1069-1074, 2013.

15. Chamberlain MC: Leptomeningeal metastasis. Curr Opin Oncol 22: 627-635, 2010 .

16. Le Rhun E, Taillibert S and Chamberlain MC: Carcinomatous meningitis: Leptomeningeal metastases in solid tumors. Surg Neurol Int 4 (Suppl 4): S265-S288, 2013.

17. Berg SL and Chamberlain MC: Systemic chemotherapy, intrathecal chemotherapy, and symptom management in the treatment of leptomeningeal metastasis. Curr Oncol Rep 5: 29-40, 2003.

18. Martins SJ, Azevedo CR, Chinen LT, Cruz MR, Peterlevitz MA and Gimenes DL: Meningeal carcinomatosis in solid tumors. Arq Neuropsiquiatr 69: 973-980, 2011.

19. Brem SS, Bierman PJ, Brem H, Butowski N, Chamberlain MC, Chiocca EA, DeAngelis LM, Fenstermaker RA, Friedman A, Gilbert MR, et al: Central nervous system cancers. J Natl Compr Canc Netw 9: 352-400, 2011.

20. Gwak HS, Lim HS, Shin SH, Yoo H, Han JY, Kim HT, Yun T, Lee JS and Lee SH: Ventriculolumbar perfusion chemotherapy for the treatment of leptomeningeal carcinomatosis: A phase I study with pharmacokinetic data. Am J Clin Oncol 36: 491-499, 2013.

21. Nakagawa H, Yamada M, Maeda N, Iwatsuki K, Hirayama A and Ikenaka K: Clinical trial of intrathecal administration of 5-fluoro-2'-deoxyuridine for treatment of meningeal dissemination of malignant tumors. J Neurooncol 45: 175-183, 1999.

22. Nakagawa H, Fujita T, Kubo S, Izumoto S, Nakajima Y, Tsuruzono K, Tokiyoshi K and Hayakawa T: Ventriculolumbar perfusion chemotherapy with methotrexate and cytosine arabinoside for meningeal carcinomatosis: A pilot study in 13 patients. Surg Neurol 45: 256-264, 1996. 
23. Gwak HS, Joo J, Kim S, Yoo H, Shin SH, Han JY, Kim HT, Lee JS and Lee SH: Analysis of treatment outcomes of intraventricular chemotherapy in 105 patients for leptomeningeal carcinomatosis from non-small-cell lung cancer. J Thorac Oncol 8: 599-605, 2013.

24. Park JH, Kim YJ, Lee JO, Lee KW, Kim JH, Bang SM, Chung JH Kim JS and Lee JS: Clinical outcomes of leptomeningeal metastasis in patients with non-small cell lung cancer in the modern chemotherapy era. Lung Cancer 76: 387-392, 2012.

25. Hitchins RN, Bell DR, Woods RL and Levi JA: A prospective randomized trial of single-agent versus combination chemotherapy in meningeal carcinomatosis. J Clin Oncol 5: 1655-1662, 1987.

26. Grossman SA, Finkelstein DM, Ruckdeschel JC, Trump DL, Moynihan T and Ettinger DS: Randomized prospective comparison of intraventricular methotrexate and thiotepa in patients with previously untreated neoplastic meningitis. Eastern Cooperative Oncology Group. J Clin Oncol 11: 561-569, 1993.

27. Kim DY, Lee KW, Yun T, Park SR, Jung JY, Kim DW, Kim TY, Heo DS, Bang YJ and Kim NK: Comparison of intrathecal chemotherapy for leptomeningeal carcinomatosis of a solid tumor: Methotrexate alone versus methotrexate in combination with cytosine arabinoside and hydrocortisone. Jpn J Clin Oncol 33: 608-612, 2003

28. Kumthekar P, Grimm SA, Avram MJ, Kaklamani V, Helenowski I, Rademaker A, Cianfrocca M, Gradishar W, Patel J, Mulcahy M, et al: Pharmacokinetics and efficacy of pemetrexed in patients with brain or leptomeningeal metastases. J Neurooncol 112: 247-255, 2013.

29. Yoshida S and Morii K: Intrathecal chemotherapy for patients with meningeal carcinomatosis. Surg Neurol 63: 52-55; discussion $55,2005$.

30. List J, Moser RP, Steuer M, Loudon WG, Blacklock JB and Grimm EA: Cytokine responses to intraventricular injection of interleukin 2 into patients with leptomeningeal carcinomatosis: Rapid induction of tumor necrosis factor alpha, interleukin 1 beta, interleukin 6, gamma-interferon, and soluble interleukin 2 receptor (Mr 55,000 protein). Cancer Res 52: 1123-1128, 1992.

31. Chen YM, Chen MC, Tsai CM and Perng RP: Intrathecal gemcitabine chemotherapy for non-small cell lung cancer patients with meningeal carcinomatosis-a case report. Lung Cancer 40 99-101, 2003

32. Glantz MJ, Jaeckle KA, Chamberlain MC, Phuphanich S, Recht L, Swinnen LJ, Maria B, LaFollette S, Schumann GB, Cole BF and Howell SB: A randomized controlled trial comparing intrathecal sustained-release cytarabine (DepoCyt) to intrathecal methotrexate in patients with neoplastic meningitis from solid tumors Clin Cancer Res 5: 3394-3402, 1999.

33. Groves MD, Glantz MJ, Chamberlain MC, Baumgartner KE Conrad CA, Hsu S, Wefel JS, Gilbert MR, Ictech S, Hunter KU, et al: A multicenter phase II trial of intrathecal topotecan in patients with meningeal malignancies. Neuro Oncol 10: 208-215, 2008.
34. Jaeckle KA, Batchelor T, O'Day SJ, Phuphanich S, New P, Lesser G, Cohn A, Gilbert M, Aiken R, Heros D, et al: An open label trial of sustained-release cytarabine (DepoCyt) for the intrathecal treatment of solid tumor neoplastic meningitis. J Neurooncol 57: 231-239, 2002.

35. Sun JM, Nam MH, Chung JY, Im B, Lee SY, Suh YL, Ahn JS, Park K and Ahn MJ: Safety and pharmacokinetics of intrathecal administration of pemetrexed in rats. Cancer Chemother Pharmacol 68: 531-538, 2011.

36. Chamberlain MC: A phase II trial of intra-cerebrospinal fluid alpha interferon in the treatment of neoplastic meningitis. Cancer 94: 2675-2680, 2002.

37. Chamberlain MC, Tsao-Wei DD and Groshen S: Phase II trial of intracerebrospinal fluid etoposide in the treatment of neoplastic meningitis. Cancer 106: 2021-2027, 2006.

38. Chamberlain M, Soffietti R, Raizer J, Rudà R, Brandsma D, Boogerd W, Taillibert S, Groves MD, Le Rhun E, Junck L, et al: Leptomeningeal metastasis: A Response Assessment in Neuro-Oncology critical review of endpoints and response criteria of published randomized clinical trials. Neuro Oncol 16: 1176-1185, 2014

39. Riess JW, Nagpal S, Iv M, Zeineh M, Gubens MA, Ramchandran K, Neal JW and Wakelee HA: Prolonged survival of patients with non-small-cell lung cancer with leptomeningeal carcinomatosis in the modern treatment era. Clin Lung Cancer 15: 202-206, 2014.

40. Heimberger AB, Learn CA, Archer GE, McLendon RE, Chewning TA, Tuck FL, Pracyk JB, Friedman AH, Friedman HS, Bigner DD and Sampson JH: Brain tumors in mice are susceptible to blockade of epidermal growth factor receptor (EGFR) with the oral, specific, EGFR-tyrosine kinase inhibitor ZD1839 (iressa). Clin Cancer Res 8: 3496-3502, 2002.

41. Omuro AM, Kris MG, Miller VA, Franceschi E, Shah N, Milton DT and Abrey LE: High incidence of disease recurrence in the brain and leptomeninges in patients with nonsmall cell lung carcinoma after response to gefitinib. Cancer 103: 2344-2348, 2005.

42. Palmieri D, Chambers AF, Felding-Habermann B, Huang S and Steeg PS: The biology of metastasis to a sanctuary site. Clin Cancer Res 13: 1656-1662, 2007.

43. Togashi Y, Masago K, Masuda S, Mizuno T, Fukudo M, Ikemi Y, Sakamori Y, Nagai H, Kim YH, Katsura T and Mishima M: Cerebrospinal fluid concentration of gefitinib and erlotinib in patients with non-small cell lung cancer. Cancer Chemother Pharmacol 70: 399-405, 2012.

44. Chamberlain MC, Junck L, Brandsma D, Soffietti R, Raizer JJ, Ruda R, Boogerd W, Taillibert S, Groves MD, Le Rhun E, et al: Leptomeningeal metastases: A rano proposal for response criteria. J Clin Oncol (suppl) 32: abstr e13019 2014. 